\title{
Physico-chemical Characteristics and Dewatering Aptitude of sMBR Sludge
}

\author{
W. Khongnakorn ${ }^{1 *}$, S. P. Choksuchart ${ }^{2}$ \& C. Wisniewski ${ }^{3}$ \\ ${ }^{1}$ Faculty of Technology and Management, Prince of Songkla University (PSU), Suratthani Campus 84100, \\ Thailand \\ ${ }^{2}$ Department of Civil Engineering, Prince of Songkla University 90112, Thailand \\ ${ }^{3}$ UMR Génie des Procédés Eau et Bioproduits- CIRAD 016, Laboratoire de Physique Moléculaire et Structurale, \\ UFR des Sciences Pharmaceutiques et Biologiques, 15 Avenue Charles Flahault BP 1449134093 \\ MONTPELLIER, France
}

\begin{abstract}
Biomass concentrations 2 to 5 times higher than in a conventional activated sludge (CAS) process can be achieved in a membrane bioreactor system (MBR). These non-conventional operating conditions, i.e. high sludge concentration, can induce different sludge characteristics and dewatering aptitude, essential parameters for the optimization of the sludge post-treatment, like mechanical dewatering. The objective of this work is to study the dewatering behavior of MBR sludge, and particularly the influence of high total suspended solids concentration, on viscosity and on the key dewaterability indicators. Operating conditions are chosen to obtain MBR sludge with constant characteristics, except TSS concentration. The results confirm that the sludge viscosity is dependent on the TSS concentration. The high viscosity obtained for high TSS concentration can be unfavorable to an efficient mixing in the MBR unit, as well as to acceptable membrane permeability. However, good settleability is obtained with high TSS concentration although the sludge presents high compressibility property and a large part of bound water. This large part of bound water seems to not disturb the sludge filterability, which stays relatively good in comparison with CAS. Consequently, high-TSS concentration in MBR system can be coherent with an efficient sludge post-treatment.
\end{abstract}

Keywords: Sludge characteristic, MBR, dewaterability, CST

\subsection{INTRODUCTION}

The membrane bioreactor (MBR) is based on the combination of a suspended biomass reactor and a separation step on porous membrane filtration. The MBR process is an emerging technology that has been successfully applied for municipal and industrial wastewater treatment at an ever increasing number of locations around the world. The MBR system combines ultrafiltration technology with biological treatment. It combines

+Correspondence to: W. Khongnakorn (email: watsa.k@psu. ac.th) clarification, aeration and filtration into a simple and cost-effective process that reduces capital and operating costs. The result is consistent, high quality effluent suitable for any discharge or reuse application. With the substitution of the settling tank by the filtration unit, biomass concentration 2 to 5 times higher than in a conventional activated sludge (CAS) process can be achieved in a MBR system. The MBR capability of higher biomass concentration and total biomass retention induce a possible space requirement reduction and a possible sludge production minimization $[1,2]$. These non-conventional operating conditions, i.e. high sludge con- 
centration and high solid retention time, can also induce different sludge characteristics and dewatering aptitude, which are essential parameters for the optimization of the sludge posttreatment, like mechanical dewatering. The objective of this work is to study the dewatering behavior of MBR sludge, and particulary the influence of high total suspended solids concentration, on the key dewaterability indicators like the specific resistance to filtrate, the dryness limits, the compressibility factor and the capillary suction time. The results are discussed and the values of the typical parameters adopted to describe sludge dewaterability are compared with the ones of CAS.

\subsection{METHODS/THEORY}

\subsection{Methodology and Experimental Set-up}

The experiments are performed in a submerged membrane bioreactor with a working volume of $50 \mathrm{~L}$. Seeding sludge, mixed culture, is taken from the activated sludge of a municipal wastewater treatment plant (500 p.e.).

Different strategies could be used to obtain MBR sludge with various TSS concentrations. In this study was chosen a simple method that consists of a regularly sampling of sludge in a MBR system functioning with high solid retention time (125 days) and defined hydraulic retention time and organic loading, equal to 2 days and 0.9 $\mathrm{kgCOD} \cdot \mathrm{m}^{-3} \cdot \mathrm{d}^{-1}$, respectively. The system is fed with a synthetic effluent, composed of acetate and meat extract (Viandox (B). The operating condition and the characteristics of the filtration unit are given in Table 1 .

\subsection{Analytical Methods}

Conventional parameters (Chemical Oxygen Demand (COD), Total Suspended Solids (TSS) and Volatile Suspended Solids (VSS)) are determined, following the standard methods [3], in the influent, the treated effluent, the bulk suspension and the soluble fraction of the bulk suspension. The soluble fraction is obtained after a centrifugation $(10000 \mathrm{~g}, 20$ minutes), following by a filtration of the supernatant through a 0.45 $\mu \mathrm{m}$ filter. Proteins and polysaccharides, mainly soluble microbial products (SMP), are quantified in the soluble fraction of the bulk suspension and are analyzed by Lowry and Anthrone method, respectively.

The dewaterabilty aptitude of the sludge (i.e. the bulk suspension) is represented by specific resistance to filtration at 0.5 bar (SRF), compressibility coefficient (s), dryness limit (Slim), sludge volume index (SVI) and capillary suction

Table 1 Experimental set-up characteristics

\begin{tabular}{rll}
\hline Operating condition & \\
& Reactor volume & $50 \mathrm{~L}$ \\
HRT & $2 \mathrm{~d}$ \\
SRT & $125 \mathrm{~d}$ \\
Organic loading rate & $0.9 \mathrm{kgCOD} \cdot \mathrm{m}^{-3} \cdot \mathrm{d}^{-1}$ \\
COD:N:P & $100: 13: 1$ \\
DO & $>5 \mathrm{mg} \cdot \mathrm{L}^{-1}$ \\
pH & $7.5 \pm 1.0$ \\
Temperature & $20 \pm 0.5^{\circ} \mathrm{C}$
\end{tabular}

Filtration unit

Membrane Capillary polysulphone hollow fibre membranes

Filtration area $\quad 0.2 \mathrm{~m}^{2}$

Pore size $\quad 0.08 \mu \mathrm{m}$

Permeate flux $\quad 5 \mathrm{~L} \cdot \mathrm{m}^{-2} \cdot \mathrm{h}^{-1}$

Aeration flow rate per filtration area $\quad 1.2 \times 10^{4} \mathrm{~L} \cdot \mathrm{m}^{-2} \cdot \mathrm{h}^{-1}$ 
Table 2 Measured parameters and methodologies

\begin{tabular}{|c|c|}
\hline Parameters & Methodologies \\
\hline COD & Digestion method and Colorimetric determination \\
\hline TSS, VSS, SVI & According to [3] \\
\hline Granulometric distribution & Malvern Mastersizer \\
\hline Apparent viscosity & Haake Rheometer (Rheostress RS 100) \\
\hline SFR, $s$ and $S_{\text {lim }}$ & $\begin{array}{l}\text { Stirred and pressurized filtration cell (Amicon 8010) with membrane } \\
\text { cellulose nitrate, } 0.2 \mu \mathrm{m} \text { (Sartorius) }\end{array}$ \\
\hline CST & According to method 2710G, Triton 319 \\
\hline \multicolumn{2}{|l|}{ SMP } \\
\hline $\begin{array}{r}\text { Proteins } \\
\text { Polysaccharides }\end{array}$ & $\begin{array}{l}\text { Lowry method using Bovine Serum Albumin as the standard } \\
\text { Anthrone method using sucrose as the standard }\end{array}$ \\
\hline
\end{tabular}

time (CST). SRF, s and Slim are measured thanks to a stirred and pressurized filtration cell (Amicon $8010)$ with membrane cellulose nitrate, $0.2 \mu \mathrm{m}$ (Sartorius). Capillary suction time (CST) is measured according to method 2710G [3] by Triton 319.

Apparent viscosity is determined using a coaxial measurement device with a double gap measuring system. The size distribution of the flocs is determined by a Malvern Mastersizer instrument and measured by means of light scattering.

The measured parameters and methodologies used are specified in Table 2.

\subsection{RESULTS AND DISCUSSIONS}

\subsection{TSS Evolution and Characteristics of the Sludge}

Figure 1 shows the evolution of TSS concentration in the bulk suspension

The TSS increase is coherent with the high SRT imposed to the system $[4,5]$. Because of a possible change during time of the chemical composition and morphological property of the sludge, some complementary analyses are performed to make sure that the other characteristics of the sludge are constant or do not change significantly during the operation time. VSS/TSS and COD/VSS ratios, as well as the mean floc size, one of the main morphological properties of the sludge, are chosen as representative para-

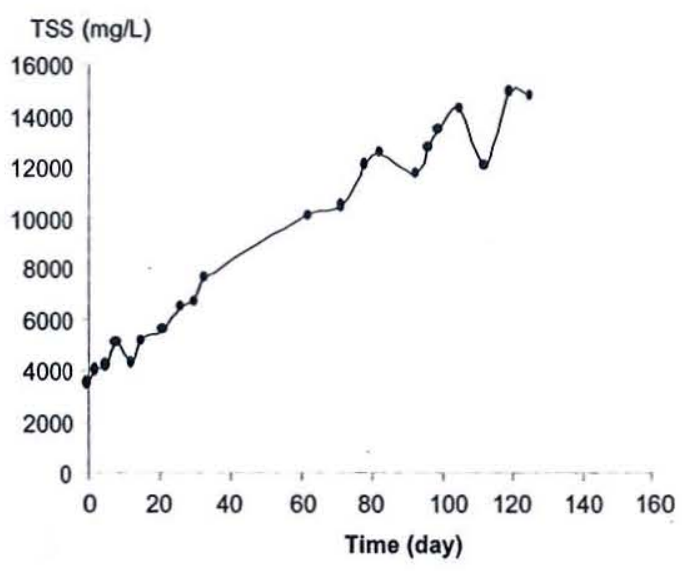

Figure 1 Evolution of TSS in the MBR system

meters of the bulk suspension. The concentration in soluble microbial products (SMP) is also measured and expressed by sum of protein and polysaccharide substances.

COD/VSS ratio, equal to $1.40 \mathrm{kgCOD} / \mathrm{kgVSS}$, seems to be independent of time and of the TSS concentration (Figure 2). This ratio value is close to the theoretical one $(1.42 \mathrm{kgCOD} / \mathrm{kgVSS})$ and the one measured in CAS and MBR system $[2,4$, $6]$. The presence of some mineral suspended solids in the reactor, coming from the influent (notably from Viandox ${ }^{\circledR}$ ), can explain the relatively low VSS/TSS ratio obtained $(0.66 \mathrm{kgVSS}$ / kgTSS) and the slight decrease observed during the operation time.

Concerning the particle size distribution, it appears that the distribution is a Gaussian 


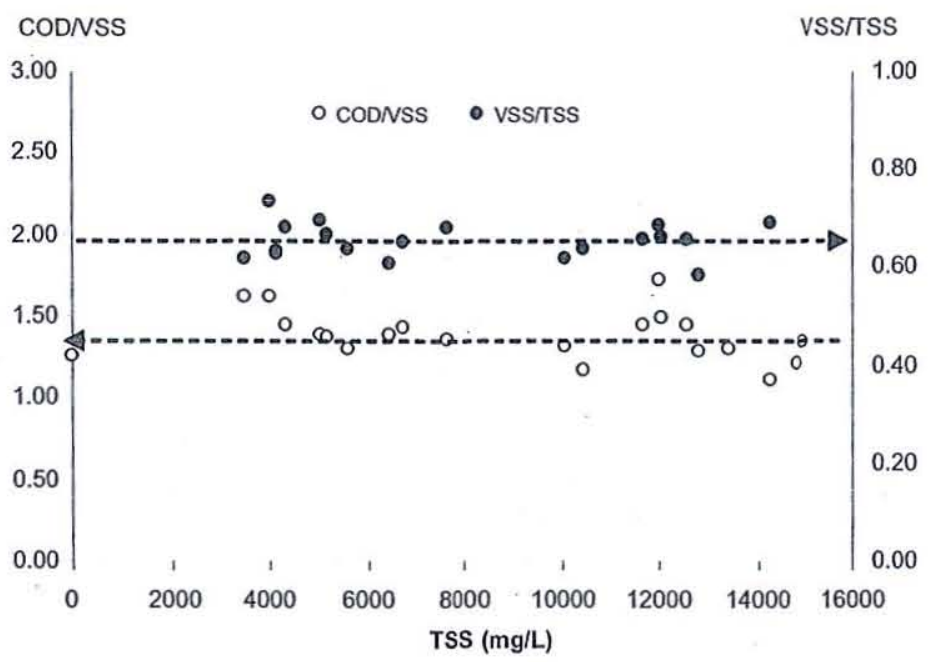

Figure 2 VSS/TSS and COD/VSS evolution versus TSS

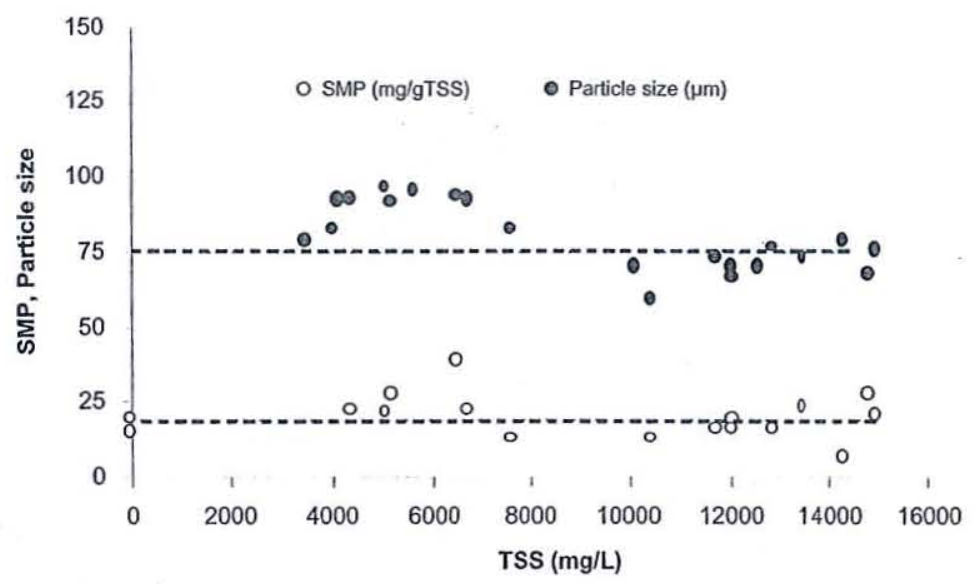

Figure 3 Particle size distribution (d) and SMP versus TSS

distribution and stays homogenous during the operation time with a very low standard deviation. The mean particle size, $d$, is closed to $80 \mu \mathrm{m}$ and does not change significantly with time and the TSS concentration (Figure 3). It is specified that contrary results are reported by Massé [7] that observed significant modifications in sludge floc size during time with high SRT conditions.

Analyses of SMP are performed because these polymeric components can have a significant contribution to enhance the sludge dewaterability [8]. Proteins and polysaccharides, considered as the mainly SMP, are quantified in the soluble fraction of the bulk suspension. No significant change in the concentration of these compounds is observed during the operation time (Figure 3).

\subsection{Physical Properties and Dewaterability of High-TSS Sludge}

\subsubsection{TSS and Sludge Viscosity}

Conventional activated sludge is well-known to be a non-Newtonian fluid, i.e. the apparent viscosity depends on the shear rate. The apparent viscosity of the sludge is a reflection of internal 


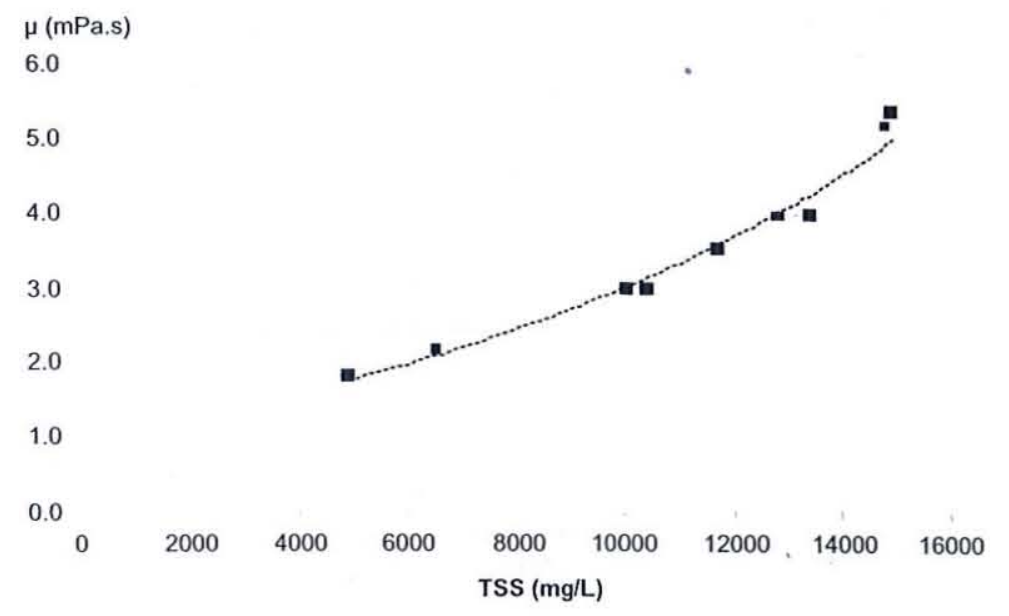

Figure $4 \mu_{\mathrm{tn}}$ versus TSS

and external interaction forces occurring within the sludge flocs and fluids, and describes the deformation of the flocs under the influence of stresses.

In the experiments, the evolution of the apparent viscosity as a function of the shear rate can be described as following: after the first Newtonian plateau, the viscosity decreases rapidly (rheofluidification) and then becomes almost constant (the second Newtonian plateau). This constant viscosity, called "limit viscosity" and denoted $\mu_{\infty}$, is used to characterize the sludge in this study. An exponential law is found to be suitable to describe the variation of the viscosity as a function of TSS (Figure 4):

$$
\mu_{\infty}=1.03 \times \exp ^{0.106 \times T S S}
$$

with $\mu_{\infty}$ in mPa.s and TSS in g. $\mathrm{L}^{-1}$.

The exponent value is found equal to 0.106 , and ranges from 0.045 to 0.23 in MBR system, values reported by Judd [6]. The exponential evolution of the viscosity with TSS concentration has also been observed by several authors in CAS and MBR system $[9,10,11]$. According to Sanin [12], this exponential pattern can explain the stronger non-Newtonian behavior of the sludge with increasing solids concentration.

The dependence of the viscosity with the TSS concentration can be considered as a brake to high-SRT operation. Indeed, high viscosity is unfavorable to an efficient mixing in the MBR unit, as well as steady membrane permeability [5]. It can be specified that, in MBR system, the notion of "critical" value of TSS has been introduced by several authors $[5,13,14]$.

Nevertheless, it can be noticed that, despite high TSS concentration, the viscosity value stays approximately close to the one measured on activated sludge at $4 \mathrm{~g} \mathrm{TSS} . \mathrm{L}^{-1}\left(5 \mathrm{mPa} . \mathrm{s}^{-1}[15]\right)$. This difference can be probably due to the particular morphology of the MBR floc, and notably to the reduced size of the floc in comparison with CAS system [8].

\subsubsection{TSS and Dewaterability}

The dewaterabilty aptitude of the sludge is represented by specific resistance to filtration (SRF), compressibility coefficient (s), dryness limit $\left(\mathrm{S}_{\text {lim }}\right)$, sludge volume index (SVI) and capillary suction time (CST). There are quantified and plotted as a function of the TSS concentration (Figure 5).

Mikkelsen and Keiding [16] stated that for a specific sludge, the CST, like viscosity, is related and dependant on the suspended solids concentration. Figure 5(a) shows a constant increase of the CST with the TSS concentration. According to Jin et al. [15] and Smollen [17], a high value of CST usually implies a poor dewaterability and corresponds to a high content of bound water. However, the difficulty is that the CST test does not quantify a particular, 


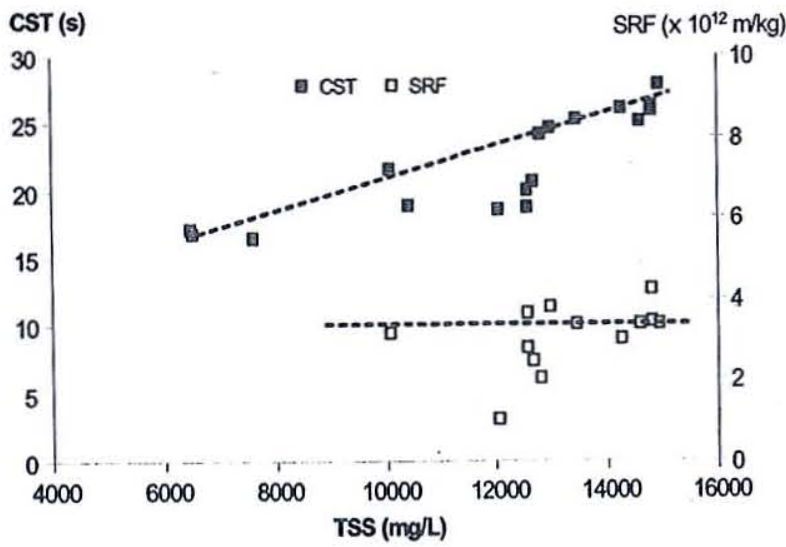

(a)

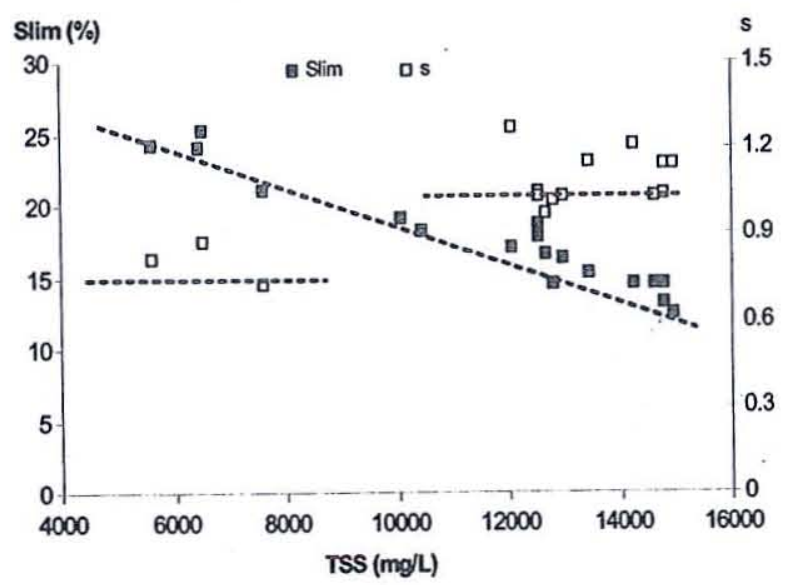

(b)

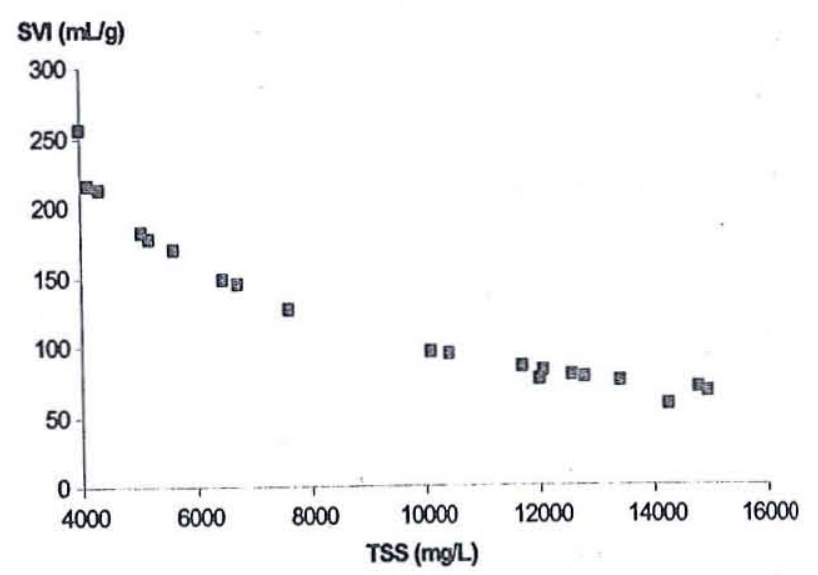

(c)

Figure 5 Dewaterability parameters versus TSS 
fundamentally based physical parameter of the sludge. While efforts to correlate the CST measurement with the basic physical properties of the sludge, there is no assurance that it will invariably predict the efficiency of a specific dewatering device [15]. On the other hand, Smollen [17] specifies that even if the water passes through the filter cake quickly, the water content inside small pores and capillaries, as well as water bound inside the floc matrix, may remain high. Therefore, the CST may strongly relate to the "free" water in the activated sludge, whereas the bound water content may be related to the internal and external molecular binding force in the sludge flocs.

In these experiments, it is observed that the dryness limit decrease with the TSS concentration. The decrease of $\mathrm{S}_{\text {lim }}$ with the TSS concentration signifies that the quantity of water in the filtration cake increases with the TSS concentration. As a consequence, this results signifies that the quantity of mechanically extractable water decrease. This result is coherent with the CST evolution and with the fact that the quantity of bound water, or "not free" water, increases with the TSS concentration.

SVI decreases with the TSS concentration, which signifies that the compressibility increases with TSS concentration. Indeed, the compressibility is generally evaluated by the sludge volume index. This increase of the compressibility is supported by the increase of the compressibility coefficient, $\mathrm{s}$, which increases from 0.8 to 1.1 . However, the MBR sludge demonstrates good settleability, the SVI being lower than $150 \mathrm{~mL} \cdot \mathrm{g}^{-1}$ for TSS concentration high more than 6 g. $\mathrm{L}^{-1}$. This result seems to demonstrate that high sludge concentration, in MBR system, does not lead to poor settling properties, which is not the case in CAS system for high sludge concentration.

No real increase of SRF is observed with the TSS concentration, demonstrating that the filterability of the MBR sludge is independent of the TSS concentration. The SRF value is quite constant, close to $310^{12} \mathrm{~m} \cdot \mathrm{kg}^{-1}$, and sensibly lower than the ones obtained for activated sludge, ranged from 4 to $1210^{13} \mathrm{~m} \cdot \mathrm{kg}^{-1}$ [18]. However, this value is close to those obtained in other MBR system [19]. This result shows that the SRF value can not be correlated to the CST value. If the CST value gives information about the bound water and/of the rate of the departure of the free water from the sludge cake, this parameter does not give a good information about the filterability (i.e. hydraulic resistance) of the sludge or the characteristics of the cake layer. These characteristics are not only dependant of the bound water, that seems to correlate with the TSS concentration (see CST and $\mathrm{S}_{\mathrm{lim}}$ values), but also of the intensity of the interaction forces between the flocs and in the flocs (e.g. between cells and extracellular polymer substances, EPS). On the other hand, Chang and Kim [20] observe an increase of the SRF with a decrease of the TSS concentration, which may demonstrate the role of other key parameters (EPS concentration, floc morphology ...) on the sludge filterability.

\subsection{CONCLUSIONS}

The objective of this work was to study the dewatering behaviour of MBR sludge, and particulary the influence of high total suspended solids concentration, on the key dewaterability indicators like the specific resistance to filtrate, the dryness limits, the compressibility factor and the capillary suction time. Operating conditions are chosen to obtain MBR sludge with constant characteristics, expect TSS concentration. The results confirm the TSS concentration influence on the sludge viscosity. The high viscosity obtained for high TSS concentration can be unfavorable to an efficient mixing in the MBR unit, as well as to acceptable membrane permeability. However, good settleability is obtained with high TSS concentration although the sludge presents high compressibility property and a large part of bound water. This large part of bound water seems to not disturb the filterability of the sludge, which stays relatively good in comparison with CAS. As a consequence of the results, the morphology and the pysical properties of the sludge flocs are supposed to have more significant influence on dewaterability than the TSS concentration. 
Consequently, high SRT conditions in MBR system, and high-TSS concentration, can be coherent with an efficient sludge post-treatment. However, a relatively low dryness limit is obtained, that can be problematic for sludge management and/or sludge specific valorisation.

\section{REFERENCES}

[1] Rosenberger, S., U. Krüger, R. Witzig, W. Manz, U. Szewzyk, and M. Kraume. 2002. Performance of a Bioreactor with Submerged Membranes for Aerobic Treatment of Municipal Waste Water. Wat. Res. 36: 413-420.

[2] Lobos, J., C. Wisniewski, M. Heran, and A. Grasmick. 2006. Membrane Bioreactor Performances: Comparison between Continuous and Sequencing Systems. Desalination 199: 319-321.

[3] APHA. 1992. Standard Methods for the Examination of Water and Wastewater. $18^{\text {th }}$ Ed. Mary Ann H. Franson, U.S.A.

[4] Orantes, J., C. Wisniewski, M. Heran, and A. Grasmick. 2004. Influence of Total Sludge Retention on the Performance of a Submerged Membrane Bioreactor. Proceedings of International Specialized: Conference on Water Environment Membrane Technology. Seoul, Korea, June 7-10.

[5] Khongnakorn, W., C. Wisniewski; L. Pottier, and L. Vachoud. 2007. Physical Properties of Sludge in a Submerged Membrane Bioreactor and Relation with Membrane Fouling. Separation and Purification Technology. 55: 125-131.

[6] Judd, S. 2006. The MBR Book; Principles and Applications of Membrane Bioreactors in water and Wastewater Treatment. Elsevier.

[7] Massé; A., M. Spérandio, and C. Cabassud: 2006:Comparison of Sludge Characte ${ }^{-1}$ ristics and Performance of a Submerged Meríbrane Bioreactor and an Activated vsil sludge Process at High Solids Retention Timeê. Wat.'Res. 40: 2405-2415.
[8] Jin, B., B.M. Wilén, and P. Lant. 2003. A Comprehensive Insight into Floc Characteristics and their Impact on Compressibility and Settleability of Activated Sludge. Chem. Eng. J. 95: 221-234.

[9] Guibaud, G., P. Dollet, N. Tixier, C. Dagot, and M. Baudu. 2004. Characterisation of the Evolution of Activated Sludges using Rheological Neasurements. Process Biochemistry. 39: 1803-1810.

[10] Hasar, H., C. Kinaci, A. Ünlü, H. Togrul, and U. Ipek. 2004. Rheological Properties of Activated Sludge in a sMBR. Biochemical Engineering Journal. 20: 1-6.

[11] Tixier, N., G. Guibaud, and M. Baudu. 2003. Determination of some Rheological Parameters for the Characterization of Activated Sludge. Bioresource Technology. 90: 215-220.

[12] Sanin, F.D. 2002. Effect of Solution Physical Chemistry on the Rheological Properties of the Activated Sludge. Water SA. 28: 207-211.

[13] Yamamoto, K., M. Hissa, T. Mahmood, and T. Mutsuo. 1994. Direct Solid Liquid Separation using Hollow Fiber Membrane in an Activated Sludge Aeration Tank. Wat. Sci. Tech. 30: 21-27.

[14] Hong, S.P., T.H. Bae, T.M. Tak, S. Hong, and A. Randall. 2002. Fouling Control in Activated Sludge Submerged Hollow Fiber Membrane Bioreactors. Desalination. 143: 219-228.

[15] Jin, B., B.M. Wilén, and P. Lant. 2004. Impacts of Morphological, Physical and Chemical Properties of Sludge Flocs on Dewaterability of Activated Sludge. Chem. Eng. J. 98: 115-126.

[16] Mikkelsen, L.H., and K. Keiding. 2002. Physico-chemical Characteristics of Full Scale Sewage Sludges with Implication to Dewatering. Wat. Res. 36: 2451-2462.

[17] Smollen, M. 1990. Evaluation of Municipal Sludge Drying and Dewatering with Respect to Sludge Volume Reduction. Wat. Sci. Tech. 22: 153-162.

[18] Berktay, A. 1998. Properties of Sludge Produced from the Pressurized Wastewater 